\title{
FABRICATION OF 45 DEGREES TEMPLATE GRAIN BOUNDARY JUNCTIONS USING A CaO LIFT-OFF TECHNIQUE.
}

\author{
R.P.J. IJsselsteijn, D. Terpstra, J. Flokstra, and H. Rogalla.
}

Universiy of Twente, Department of Applied Physics, P.O. Box 217, 7500 AE Enschede, The Netherlands.

45 degrees grain boundary junctions have been made using (100) $\mathrm{MgO}$ substrates, a $\mathrm{CeO}_{2}$ template layer and an $\mathrm{YBa}_{2} \mathrm{Cu}_{3} \mathrm{O}_{7}$ top layer. To minimize the damage to the $\mathrm{MgO}$ surface, which will occur if the $\mathrm{CeO}_{2}$ is structured using ion milling, the $\mathrm{CeO}_{2}$ layer has been structured using the $\mathrm{CaO}$ lift-off technique. Electrical measurements of these junctions as a function of temperature, microwave irradiation and magnetic field will be discussed in this paper.

\section{INTRODUCTION}

Several types of grain boundary junctions have been discussed in literature [1-3]. Among them, the template grain boundary junction (TGBJ) offers the possibility of being placed at any wanted position on the substrate. This kind of junction consists of a template layer on part of the substrate and a toplayer of superconducting material, optionally protected from the substrate and template layer by a bufferlayer. Several possibilities exist for the choise of substrate, template and buffer material $[2,4]$. The preparation of 18 degrees grain boundaries on $\mathrm{MgO}$ as reported earlier [5] does seem to be strongly dependent on the batch of substrates.

In this paper the preparation and electrical characterization of TGBJs consisting of an $\mathrm{MgO}$ substrate, a $\mathrm{CeO}_{2}$ template layer and an $\mathrm{YBa}_{2} \mathrm{Cu}_{3} \mathrm{O}_{7}$ toplayer will be discussed.

The deposition of all layers has taken place using the pulsed laser deposition technique.

\section{PREPARATION}

Structuring the $\mathrm{CeO}_{2}$ by means of $\mathrm{Ar}$ ion beam etching, causes several peculiarities because the $\mathrm{MgO}$ substrate will also be etched. Firstly, if a step

This work is financed by the "Stichting voor Fundamenteel Onderzoek der Materie", which is financially supported by the "Nederlandse organisatie voor Wetenschappelijk Onderzoek". is etched in the $\mathrm{MgO}$ the $\mathrm{YBa}_{2} \mathrm{Cu}_{3} \mathrm{O}_{7}$ grows with its $\mathrm{c}$-axis perpendicular to the local $\mathrm{MgO}$ surface [3]. Furthermore $\mathrm{YBa}_{2} \mathrm{Cu}_{3} \mathrm{O}_{7}$ grown on an etched substrate is growing 45 degrees rotated with respect to the cubic to cubic growth normally obtained [5]. Etching of the $\mathrm{CeO}_{2}$ layer with $\mathrm{Ar}$ ions leads to severe problems concerning the definition of one single grain boundary.

To improve this definition the $\mathrm{CaO}$ lift-off technique [6] is used to structure the $\mathrm{CeO}_{2}$. To define the edge of the $\mathrm{CeO}_{2}$ first a photoresist mask (thickness $1.4 \mu \mathrm{m}$ ) is deposited and structured using standard photolithography, such that the remaining resist covers half of the substrate. Next a $400 \mathrm{~nm}$ thick amorphous $\mathrm{CaO}$ layer is deposited, followed by lift-off of the photoresist using aceton p.a. (dried with $\mathrm{K}_{2} \mathrm{CO}_{3}$ ). Deposition of a $10 \mathrm{~nm}$ thick $\mathrm{CeO}_{2}$ layer is followed by dissolving the remaining $\mathrm{CaO}$ in distilled water in 10 minutes, leaving half the substrate covered with $\mathrm{CeO}_{2}$. A $100 \mathrm{~nm}$ thick $\mathrm{YBa}_{2} \mathrm{Cu}_{3} \mathrm{O}_{7}$ layer is deposited, followed by structuring of the actual junctions (width $5-25 \mu \mathrm{m}$ ) using $\mathrm{Ar}$ ion beam etching. More details about the deposition and structuring of the layers will be published elsewhere [5].

\section{RESULTS}

\subsection{Material aspects}

The process steps prior to deposition of the $\mathrm{YBa}_{2} \mathrm{Cu}_{3} \mathrm{O}_{7}$ layer might cause contamination and structural damage of the $\mathrm{MgO}$ surface. $\mathrm{RBS}$ has been used to look for remainders of $\mathrm{Ca}$ after rinsing the 
substrate in water. No remainders have been found [5]. Possible damage of the $\mathrm{MgO}$ surface due to the water has been checked using (AR)XPS, by comparing the $\mathrm{O}(1 \mathrm{~s})$ and the $\mathrm{Mg}(2 \mathrm{p})$ peak of a treated substrate with a fresh substrate, before and after annealing both substrates to $750{ }^{\circ} \mathrm{C}$ for 30 minutes in $25 \mathrm{~Pa}$ oxygen. A difference between the $O(1 \mathrm{~s})$ peak of the treated and the fresh substrate is observed, and is probably caused by an adhesion of $\mathrm{OH}$ or $\mathrm{H}_{2} \mathrm{O}$ to the $\mathrm{MgO}$ surface. This difference disappeared after the heat treatment.

All orientatiens of the layers have been checked using $\mathrm{XRD} . \mathrm{CeO}_{2}$ and $\mathrm{YBa}_{2} \mathrm{Cu}_{3} \mathrm{O}_{7}$ both grow inplane plane cubic to cubic on the $\mathrm{MgO}$. The $\mathrm{YBa}_{2} \mathrm{Cu}_{3} \mathrm{O}_{7}$ on top of the $\mathrm{CeO}_{2}$ is 45 degrees rotated with respect to the cubic to cubic growth.

\subsection{Electrical measurements}

Apart from RSJ like IV curves of the junctions, measured at temperatures between $15 \mathrm{~K}$ and $\mathrm{T}_{\mathrm{c}}$, also much more rounded curves with reduced critical current densities are observed which will not be discussed here.

$\mathrm{I}_{c} R_{n}$ values of the junctions are typicly $0.5 \mathrm{mV}$ at

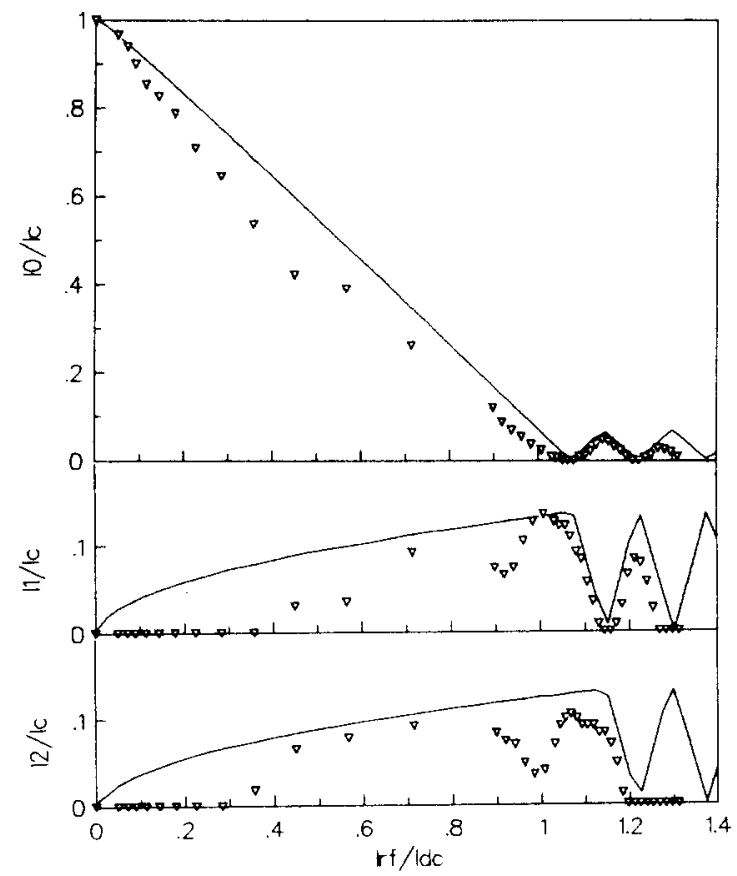

Figure 1. Normalized critical current and amplitude of the first and second Shapiro step as a function of the microwave power, including a fit according to the RSJ model.
$20 \mathrm{~K}$ and decreasing to zero at about $70 \mathrm{~K} . \mathrm{R}_{\mathrm{n}}$ values are of the order of a few Ohms between $20 \mathrm{~K}$ and $\mathrm{T}_{\mathrm{c}}$.

In figure 1 the amplitude of the critical current and the first and second Shapiro step are given as a function of the $9.64 \mathrm{GHz}$ signalpower at $44.6 \mathrm{~K}$ for a $25 \mu \mathrm{m}$ wide junction. $J_{c}$ of this junction at this temperature is $1.8 \cdot 10^{4} \mathrm{~A} / \mathrm{cm}^{2}, R_{\mathrm{n}}$ as determined by the slope of the IV curve at $100 \mu \mathrm{V}$ is $0.8 \Omega$. Also a fit according to the RSJ model is given, using a value for the $I_{c} R_{n}$ product of $285 \mu \mathrm{V}$, comparable to the value of the $I_{c} R_{n}$ product determined in the IV curve. A good fit is obtained, indicating a good Josephson behaviour that can be well described with the RSJ model.

Critical current measurements as a function of the applied magnetic field parallel to the substrate surface and the grain boundary at $55 \mathrm{~K}$, show a modulation down to zero critical current. At lower temperatures this suppression is not complete.

\section{CONCLUSIONS}

The 45 degrees template grain bondary junctions, of which the template layer is structured using the $\mathrm{CaO}$ lift-off technique show $\mathrm{I}_{c} \mathrm{R}_{\mathrm{n}}$ values up to 0.5 $\mathrm{mV}$ at $20 \mathrm{~K}$ and good Josephson behaviour. Most junctions have RSJ like IV curves. Good agreement can be obtained between the amplitudes of the induced Shapiro steps and predictions by the RSJ model. The critical current can be modulated down to zero, by applying a magnetic field parallel to the substrate surface and the grain boundary.

\section{REFERENCES}

1. D. Dimos. P. Chaudhari, J. Mannhart, and F.K. Legeous, Phys. Rev. Lett. 61, (1988), 219.

2. K. Char, M.S. Colclough, L.P. Lee, and G. Zaharchuk, Appl. Phys. Lett. 59, (1991), 2177.

3. S. Tanaka, H. Kado, T. Matsuura and H. Itozaki, ASC 1992, to be published in IEEE Transaction on Superconductivity.

4. X.D. Wu, L. Luo, R.E. Muenchausen, K.N. Springer, and S. Foltyn, Appl. Phys. Lett. 60,(1992), 1381.

5. R.P.J. IJsselsteijn, J.W.M. Hilgenkamp, M. Eisenberg, D. Terpstra, J. Flokstra, and H. Rogalla, ASC 1992, to be published in IEEE Transaction on Superconductivity.

6. B. Roas, Appl. Phys. Lett. 60, (1991), 2594. 